\title{
Geospatial Distribution and Accessibility of Primary and Secondary Schools: A case of Abbottabad City, Pakistan
}

\author{
Neema Simon Sumari ${ }^{\mathrm{a}, \mathrm{b}}$, Hashir Tanveer $^{\mathrm{a}}$, Zhenfeng Shao ${ }^{\mathrm{a}^{*}}$, Ernest Simon Kira $^{\mathrm{c}}$ \\ ${ }^{a}$ State Key Laboratory of Information Engineering in Surveying, Mapping and Remote Sensing (LIESMARS), Wuhan University 129 \\ Luoyu Road, Wuhan, China.Email: neydsumari@gmail.com, hashir@whu.edu.cn \\ ${ }^{b}$ Department of Informatics, Solomon Mahlangu College of Science and Education, Sokoine University of Agriculture P.O. Box \\ 3038, Morogoro, Tanzania.
}

${ }^{c}$ Department of Education, Solomon Mahlangu College of Science and Education, Sokoine University of Agriculture P.O. Box 3038 , Morogoro, Tanzania

* $\quad$ Correspondence: shaozhenfeng@whu.edu.cn

\begin{abstract}
:
Quality education in isolated areas is a major issue in developing countries like Pakistan, as access to formal education is linked to improved life prospects for rural students. Among the factors for education, accessibility is school availability within a minimum spatial distance. The spatial distribution of schools is generally uneven in most of the cities of Northern Pakistan, thus limiting access to formal education at the primary and secondary level. This paper analyzes the spatial distribution of the primary and secondary schools found in the hilly terrain of Abbottabad city. Results show an uneven scattered pattern of schools and decreasing accessibility with longer travel times, at higher costs. Cost-weighted distance showed that this spatial distribution extends the travel distance by more than $5 \mathrm{~km}$ for secondary school students living in the city. However, spatial restructuring and reorganization of schools in the study area would enhance student access to school facilities.
\end{abstract}

KEYWORDS: Geospatial Distribution, Accessibility, Cost-Weighted Distance, Geographical Information System, Pakistan.

\section{Introduction}

Formal education has been a priority in both developed and developing countries because of its contribution to social economic development. However, in developing countries, formal education faces a number of challenges that necessitate the formulation of various policies to facilitate its accessibility (Li, Gong, and Yue, 2014, Asiyanbola, 2017; Sumari et al., 2019). In Pakistan, participation of children in education is low as compared to the countries having a similar level of economic development (Al-Enaz, 2016). Nationwide, the primary school net enrolment rate for children ages 5-9 is 56\%$60 \%$ for males and $51 \%$ for females. Primary and secondary level education in northern Pakistan faces various challenges in the 21 st century (Tahir, Das, and Khwaja, 2008; Curtis and Scheurer, 2017). Government of Pakistan has introduced many reforms in the school sector. A government of Pakistan has committed itself to enhance the development of educational facilities more than ever since last two decades (Tahir, Das, and Khwaja, 2008; Ford et al., 2015). Accessing and utilizing these educational facilities fully is not only necessary to enhance the quality of education but also to create a corporate culture for better development and decision-making. Obstacles and challenges, however, impede access to quality education for all school-aged children, especially in hilly and isolated areas of northern Pakistan.

One dimension of accessibility to the school facilities refers to the distance that students must travel to avail themselves to services found at the school (Awoniy, 2014, Ford et al., 2015; Eksteen and Roos, 2014). The distribution of schools in different areas across varied terrain is also a factor when evaluating the accessibility of existing schools facilities. Abbottabad has harsh cold weather in winter, with hills of various heights and inclined plains, and contains small-forested areas, making travel of both teachers and students difficult. The hills and inclined plains add more time between a starting point and destination as compared to flat areas. School accessibility under the complex terrain conditions of Abbottabad is reduced when the distribution of school facilities is uneven. Accessibility is also a term used in transport and land-use planning, and can be understood as the approximate ease of reaching a destination (Whyat, Clark, and Davies, 2011). Thus, taking account of both ways of thinking about accessibility, a location is determined to be accessible if the effort one takes to get there is acceptable to the target group. Our working concept of accessibility incorporates not only the transport link to the school 
facility but also the characteristics of the destination, and the objective of the trip (Lagrab and Aknni, 2015).

Studies show that access to education at all levels helps equip people with the tools to overcome constraints to development. This is partly because accessibility motivates both teachers and students of school attendance, parent's involvement in school activities, security of the school properties and development of income generating school-based projects (Scott and Rajabifard, 2017). This implies that planning on where schools should be located especially for the day schools needs to consider its accessibility by teachers, students, and parents.

It has been observed that the use of Geographical Information System (GIS) as a study of spatial analysis can partly address the challenge of the school inaccessibility (Sumari, Shao and Kira, 2017; van Genderen, 1992; Gong et al., 2017; Anderson et al., 2017). Unfortunately, studies show that use of GIS in education issues especially in developing countries is of a low scale (Sumari, Shao, and Kira, 2017). Geoinformatics in Pakistan is in preliminary stage, which is why getting spatial and geographic information is not easy (Tahir, Das, and Khwaja, 2008). This means GIS has not been evolved fully in Pakistan as compared to other under-developing countries (van Genderen, 1991; Tahir, Das, and Khwaja, 2008). Therefore, there is a need for establishing simple and effective indicators of school accessibility that can be easily visualized.

The central objective of the study is to examine the spatial accessibility levels of students and the public to primary and secondary education institutions in Abbottabad, KPK, in Pakistan and identify the factors associated with it. The purpose is based on the observation that with help of spatial pattern of the school's location and attribute data. GIS can potentially analyze and produce accurate and best accessibility of schools where GIS-based accessibility analysis for education planning, can incorporate the expected marked area size as a key factor in the location decision making (Musakwa, 2017; Li et al., 2017b; Komba and Kira, 2013; Tate and Chen, 2014; Tate and Jarvis, 2017)

\section{Background}

An understanding of how schools are distributed spatially can aid planners to increase the accessibility level of primary and secondary schools. Geographical Information Systems (GIS) provide advanced analysis tools and complete data packages for analyzing service distribution and demographic information (van Genderen, 2017,
Shoman and Demirel, 2018). These tools can help planners in deciding such things as choosing schools locations, and identifying the optimal school's new locations (Shoma, Alganc1 and Demirel, 2018; Mokoena \& Musakwa, 2018). Ultimately, accessibility to education depends on the availability of schools within a minimum spatial distance to children across various economic levels. Settlements, roads, schools location, the number of secondary schools, and school enrolments can be used to generate mappings of school accessibility and suggest effective placement measures through network analysis (Bishop et al., 1998; Al-Enaz et al., 2016). A continuous distribution, of schools in close proximity to students, have a greater influence on the individual students than those farther away, much like distance itself (Fleischmann, 2017; Demirel and Shoman, 2017; Wang and Ye, 2018). The location of schools is optimally based on empirical factors such as population, proximity, and economic efficiency for sustainable development. A study that was carried out using nearest neighbor analysis (NNA) as the statistical tool realized that it was possible to achieve a rational distribution pattern for primary schools (Lagrab and Aknni, 2015; Al-Rasheed et al., 2013). The accessibility of a study area calculated using buffer analysis and cost-weighted distance methods efficiently and effectively identifies service areas and served population (Tahir, Das, and Khwaja, 2008). Accessibility impacts of land-use and transport strategies are often evaluated using accessibility measures that can be used for schools and other health facilities (Al-Enaz et al., 2016; Li et al., 2017a). In this study a cost-weighted distance and network analysis along with Euclidean distance method, and multiple ring buffer method are employed in a school accessibility analysis, providing extensively detailed results for empirically grounded decision making support.

\section{Methodology}

\subsection{Study Area}

Abbottabad is a city situated in the province of Khyber Pakhtunkhwa in the north of Pakistan. This city is very well known for pleasant weather, tourism, and for hosting a military academy. The district consists of many towns, divided into 51 union councils including the urban and rural areas. This research focuses on the Abbottabad city area $34^{\circ} 92^{\prime} \mathrm{N}$ latitude and $73^{\circ} 13^{\prime} \mathrm{E}$ longitude as detailed in Fig 1 below. As work has never been done in this area before, everything has had to be constructed from scratch. An integrated geospatial database was designed with multiple features and aspects, according to the characteristics of the area. The significance of building a database is an integral and important part of this study, as such a database did not exist in Abbottabad. 


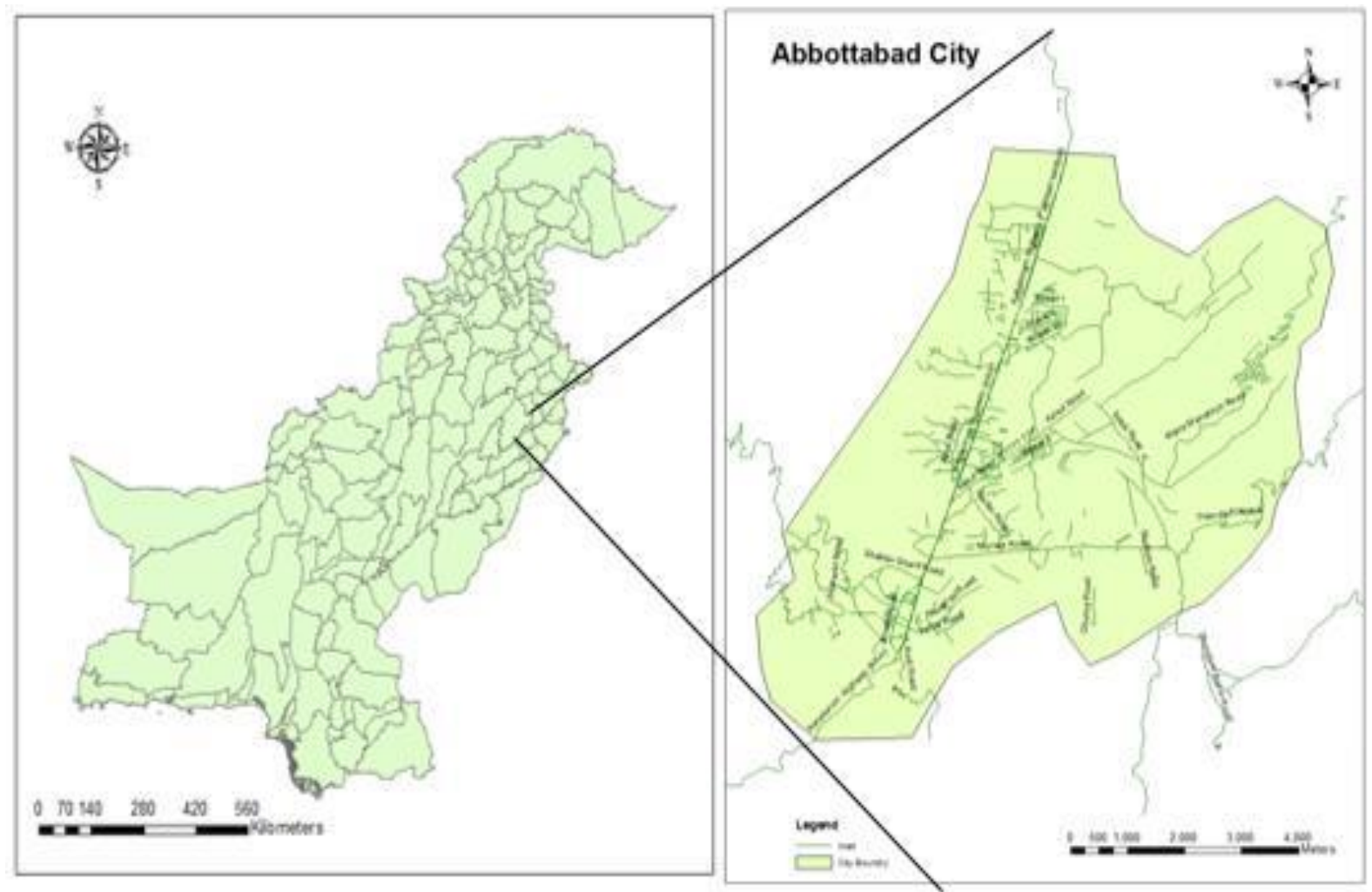

Fig 1: Location of study area the Abbottabad city in Pakistan Administrative

\subsection{Data Collection}

Primary data for this study was collected through a handheld GPS receiver to capture the location of schools. Postprimary data includes an administrative map, demographic statistics from teachers and students and statistics of the school's facilities. All maps and spatial data were captured on a GIS platform for geospatial distribution and accessibility analysis. The analysis was done in an ArcGIS environment to obtain the spatial pattern of the distribution of schools for calculating the accessibility of each school in the study area.

Road network, schools location, GPS coordinates and the number of schools, were used to generate both school accessibility and spatial analysis using network analysis and to examine: the distance among the schools, service areas for a specific radius from each school, and the optimal walk-path to reach each school facility.

\subsection{Data Pre-processing}

After collecting all the data, further processing was required for more extensive and detailed interpretation. In pre-processing the extraction of each area of interest and road network was carried out. In the processing stage, the data were subjected to multiple methods of analysis to obtain the average distance among primary and secondary school facilities and also the average distance from roads. Moreover, elevation data were included to retrieve the optimum and lowest cost distance in time and distance to the destination. Data generated during pre-processing helped in interpreting the primary data to achieve spatial distribution and accessibility results for primary and secondary schools. Most of the areas in Abbottabad District contain hills and mountains, adding complexity and obscuring an understanding of the issue of accessing schools in those areas. Geographical visualization permits identification of those areas. Visualization gives users the opportunity to analyze the distribution of schools individually and collectively and helps authorities in planning for major travel problems that occur during the harsh winter season. Fig 2 shows the exact location of each school in a particular union council on a map using GPS coordinates along with the complete details of resources at a particular school facility. 

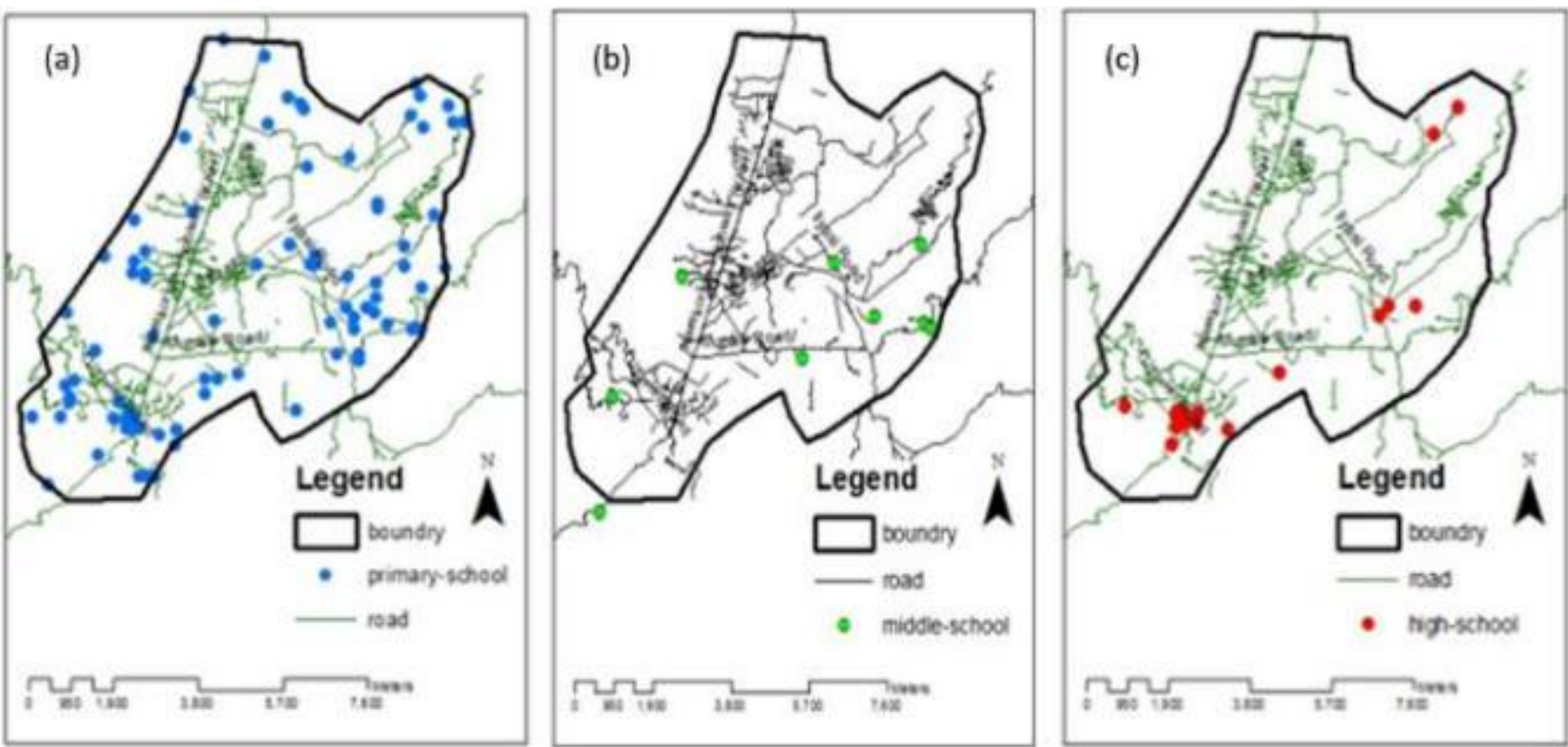

Fig 2: Distribution of (a)Primary Schools, (b) Middle Schools and (c)High Schools

\section{Results and Discussion}

\subsection{School Service Area Analysis}

GIS systems are well suited to measure spatial accessibility to educational facilities as they contain the core components needed for analysis such as buffering. To calculate the distance of schools from the buffer analysis is a very promising approach. Buffer analyses were undertaken by setting several 500-meter buffer bands in order to facilitate discussions about levels of accessibility from the main central highway. The average of this buffer bands can be calculated using standard deviation to obtain the mean value.
Standard Deviation $\quad \sigma=\sqrt{\frac{1}{\mathrm{~N}} \sum_{\mathrm{i}=1}^{\mathrm{N}}\left(\mathrm{x}_{\mathrm{i}}-\mu\right)^{2}}$

Where $x i$ is observed values of the samples, $\mu$ is the mean value of these observations and $\mathrm{N}$ is the number of observations in the sample.

In Fig 3: a distance of schools starts from less than 500 meters and it reaches up to 7.5 kilometres. Majority of primary and middle schools are at the higher distance from the central highway. This distance could be fine for middle and high school's students but certainly not feasible and safe for primary students, who have to walk to reach the school.

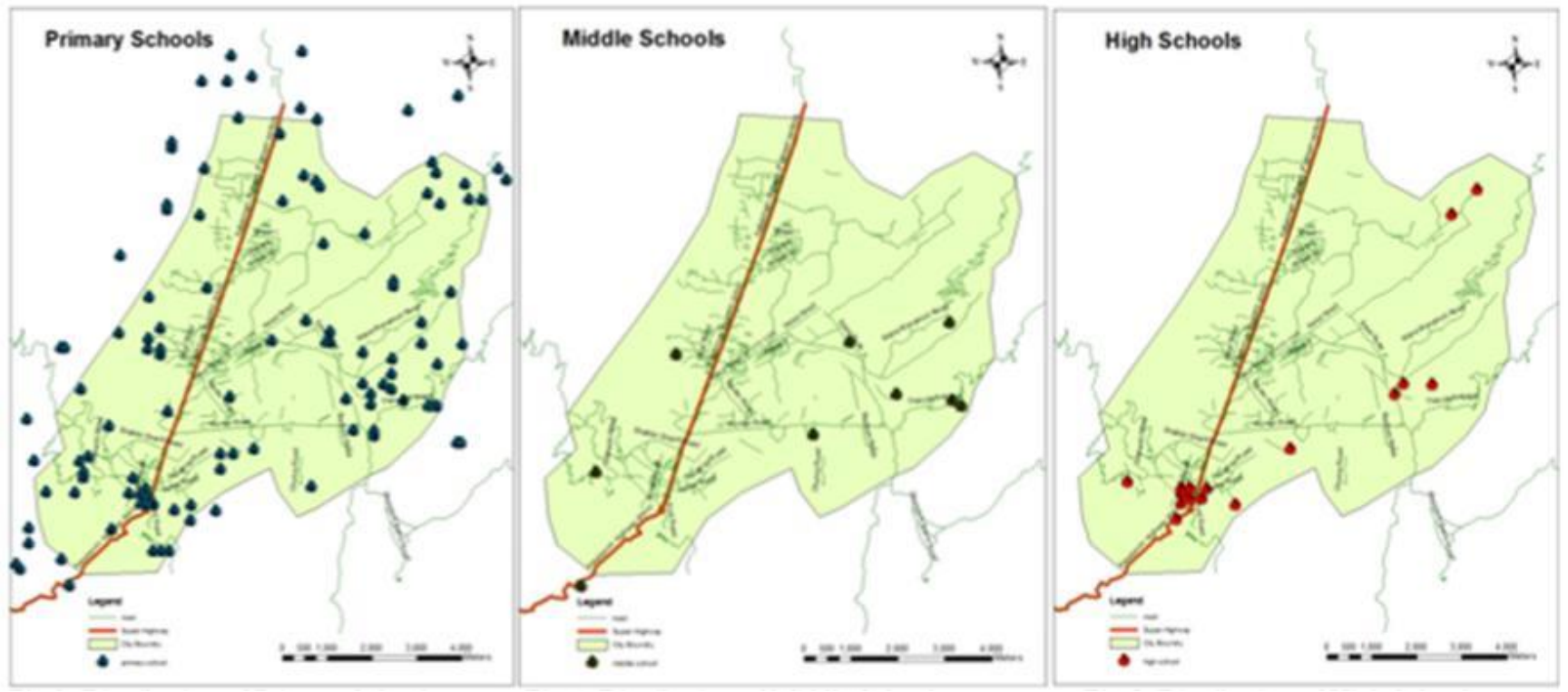

Fig 3 : Distribution of (a)Primary Schools, (b) Middle Schools and (c)High Schools 


\subsection{School Accessibility Analysis}

\subsubsection{Euclidean Distance}

Using Euclidean distance to measure the average distance from schools is efficient regardless of the area of the city, and estimates the distance of High and Middle Schools from each other as well as to other areas of the city. This method supports further time and distance analysis to measure the cost and resource consumption in accessing any particular school.

EuclideanDistance $=\sqrt{\sum_{i=1}^{n}\left(q_{i-} p_{i}\right)^{2}}$

Where $\mathrm{p}$ and $\mathrm{q}$ are two points in space.

Results of Euclidean distance analysis shown in Fig 4 (a, $\mathrm{b}$, c) below for middle, high, and primary schools respectively in the city. The distribution is random and one of the schools is outside of the city boundary in Fig 4 (a). Most of the middle schools are at a distance of one kilometre from each other but the distance for the northwestern areas are more than four kilometres, which reflects serious accessibility issues.
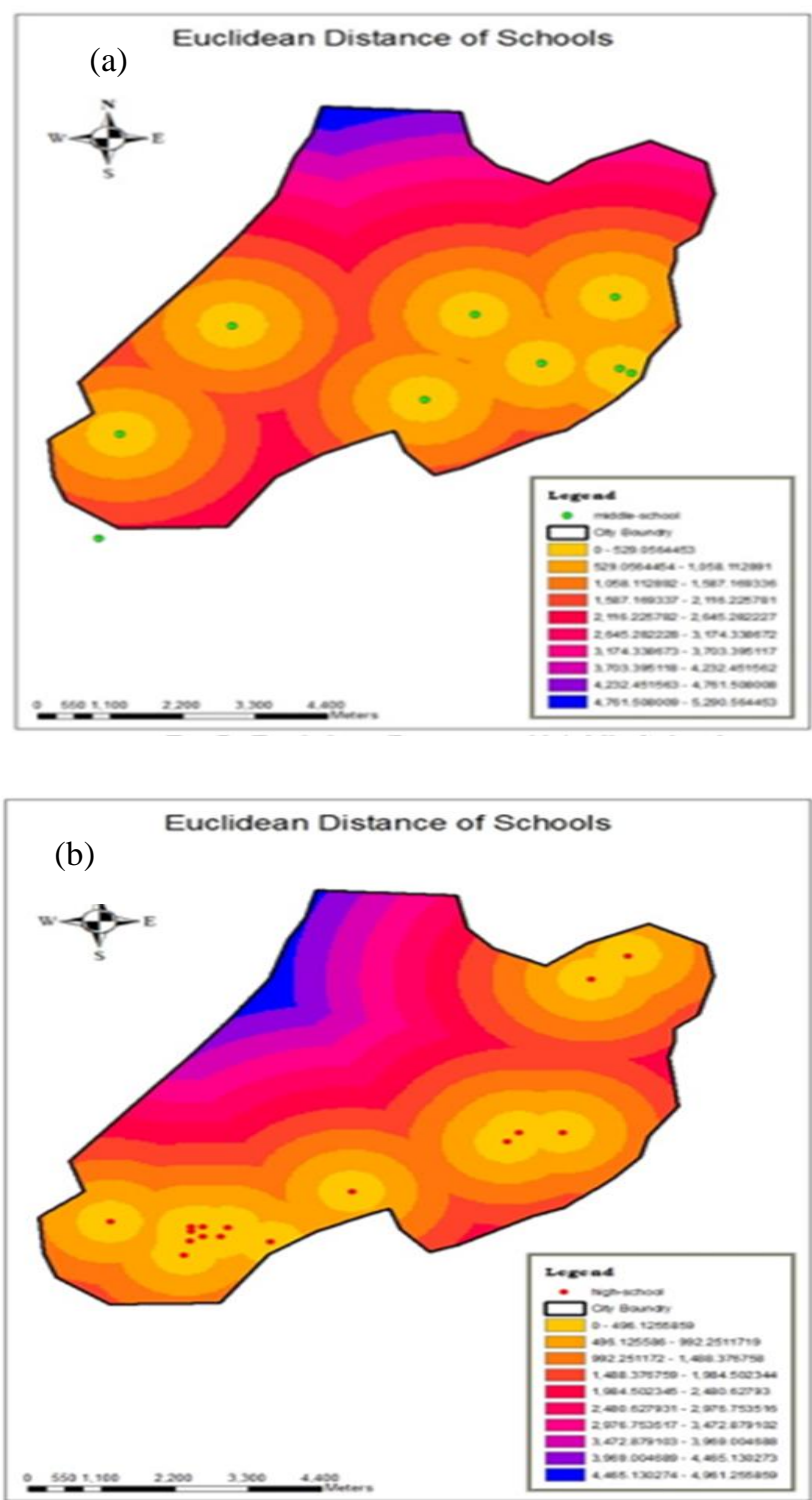

Fig $4(\boldsymbol{a}, \boldsymbol{b})$ : Eucidean Distribution for Middle and High
Fig 4 (b), shows that high schools are concentrated in a small area. There are more than six high schools within a radius of two kilometres. Most of the high schools are almost five kilometres from the western area of the city.

Fig 4 (c) shows the distribution of primary schools. Primary schools are more in number than in high and middle schools. The distribution and distance of primary schools are reasonable for general public access; but the major issue is many of the schools draw students from outside of the city boundary.

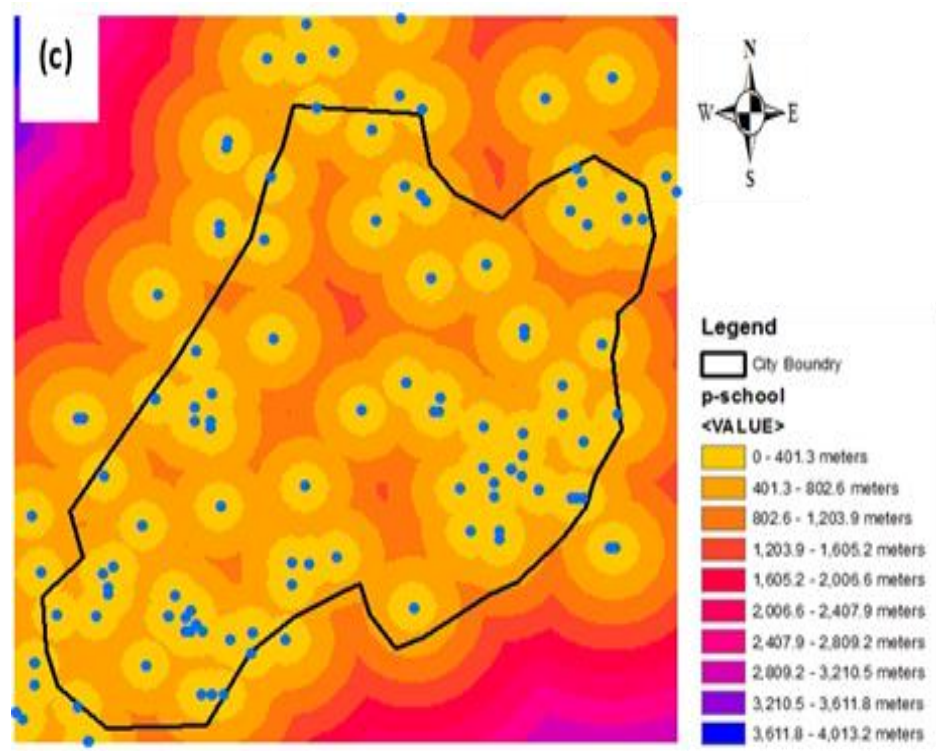

Fig 4 ( c): Eucidean Distribution for Primary school

\subsubsection{Cost-Weighted Distance}

The principle of cost-weighted distance method uses the rule that one line connects to another. Using a loop operation, the process calculates the cumulated low cost from a pixel to the center pixel of all possible paths in the study area. The moving cost is defined by the mean resistance to walking to the destination through hilly (slope) and plain areas. Statistics of minimum and maximum values of the resistance are given in Table 1 below.

Table 1: Resistance values

\begin{tabular}{|l|c|c|c|}
\hline $\begin{array}{l}\text { School } \\
\text { Type }\end{array}$ & $\begin{array}{c}\text { Minimum } \\
\text { value }\end{array}$ & $\begin{array}{c}\text { Maximum } \\
\text { Value }\end{array}$ & $\begin{array}{c}\text { Mean } \\
\text { value }\end{array}$ \\
\hline Primary & 1.00 & 83.00 & 31.40 \\
\hline Middle & 1.00 & 10.00 & 4.18 \\
\hline High & 1.00 & 18.00 & 7.91 \\
\hline
\end{tabular}

Slope levels increase as we move towards the outer parts of the city, adding more time and effort to reach a destination point. Most of the high and middle schools are not in highly inclined areas, which can reduce and save time and cost, but many primary schools are in highly inclined areas. Age of primary school students is usually 
not more than 10 years, which raises the risk for them to go to these schools, especially in cold winter conditions.

The cost-weighted distance is shown in Fig 5.

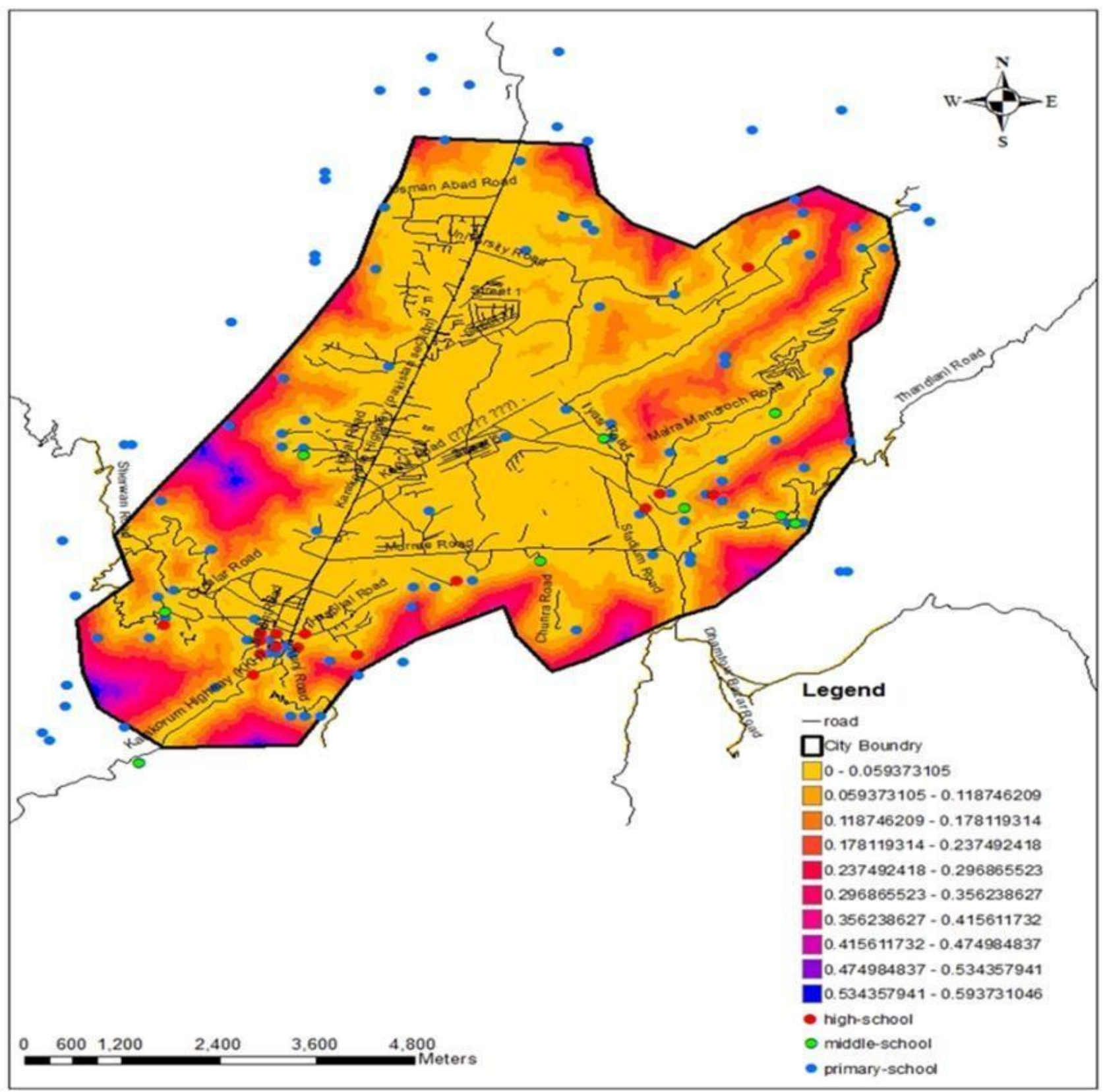

Fig 5: Cost-distance analysis from plain to slop area

Cost in the central areas of the city is at a low level, shown as yellow color in Fig 6. This cost increases moving towards the outer side, from yellow to red and blue. By understanding these cost values are related to hilly and inclined areas, indicates the best path to reach the school on foot
Many schools do not have direct road access, so students have to walk from the road to the school. This analysis found the best and lowest slope path to reach a school from the road. With the help of elevation information, this method calculated the least cost path to reach each school destination. 


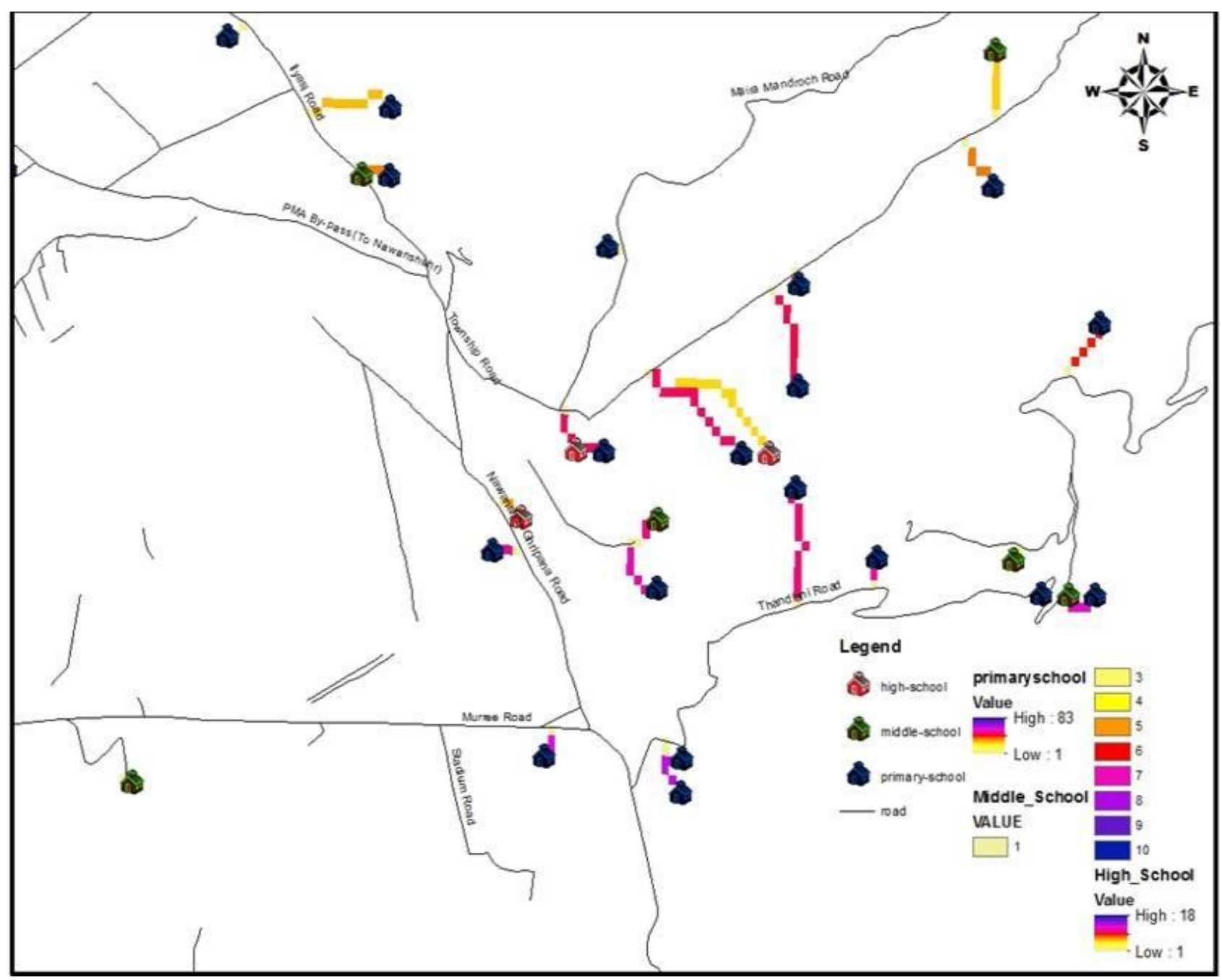

Fig 6: Cost-distance analysis from plain to slop area

\subsubsection{Road Network Analysis}

Network analysis used to find service areas around any location. Service areas visualize and aid measurement of accessibility so that school transportation problems can be reduced by finding the best paths from superhighway and student locations to schools by taking several constraints such as time and distance into consideration. Fig 7 below shows a network analysis applied in the radius of one kilometre to analyse the service area around the school facility. It aids understanding of the road network and in finding the starting and ending points of roads near schools. The analysis shows diversity in service areas among school facilities because of the distance of schools from the road. 


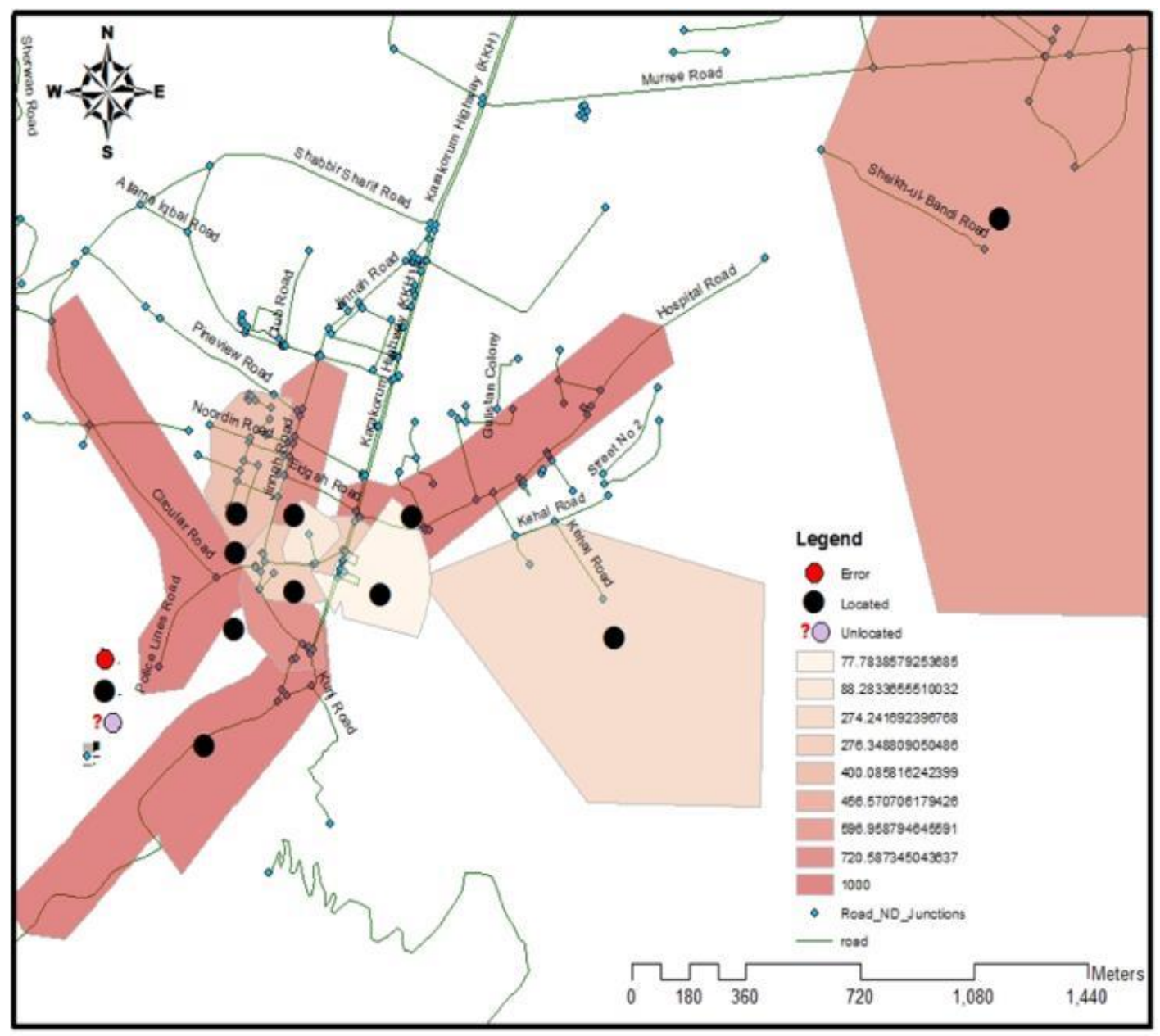

Fig 7: Service Area of roads in $1 \mathrm{~km}$ radius

\subsection{True 3D Distance}

In this process, we used digital elevation model (DEM) which access the surface to calculate the slope. We have included the two-dimensional geometry to calculate the length of the shortest path from the nearest road to school on the map. Three-dimensional analysis method used to calculate the length was considering the surface underneath.

By using, the model of "functional surface" to add the surface information, with the help of two-dimensional distance this model calculates the 3D true length of the shortest path from the nearest road to any particular school. There is a clear difference between the values of twodimensional and true three-dimensional distance because of the addition of the slope.

The reason of performing this analysis is to understand the difficulty of walk on the areas with high slop. Furthermore, it can help to calculate real distance to school; hence total time can be calculated.

In Fig 8. Below shows the shortest distance from roads to schools on the satellite image.

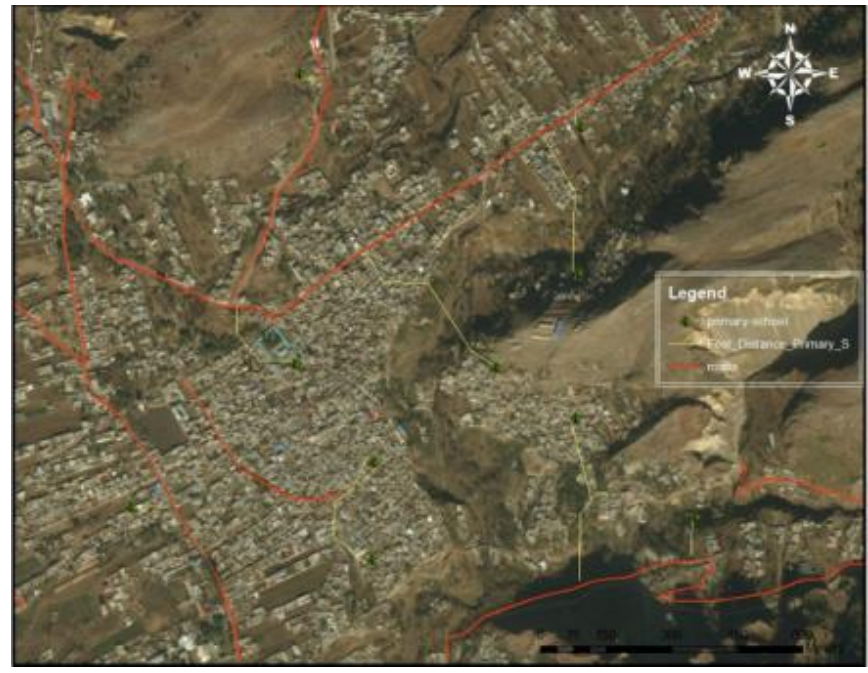

Fig 8: True Distance (Google satellite image 2016)

One of the areas used in this research as an example, to show the difference in distances (Table 2). This method helps in finding the true distance not displacementcal (Shown in the yellow 
color) which will help in calculating the average time to access the school from the nearest road in red color.

Table 2: Differentiate between the 2D distance and true distance of the shortest path

\begin{tabular}{|l|c|c|}
\hline \multicolumn{1}{|c|}{ School } & $\begin{array}{c}\text { Displacement } \\
\text { (meters) }\end{array}$ & $\begin{array}{c}\text { Actual } \\
\text { Distance } \\
\text { (meters) }\end{array}$ \\
\hline GMPS MAIRA NAWA SHER & 15.405 & 41 \\
\hline GMPS GUJAR BANDI & 310.26 & 384.97 \\
\hline GGPS DHODIAL & 419.82 & 599.67 \\
\hline GGPS NAWAN SHEHR NO One & 203.17 & 219.00 \\
\hline GGPS NAWAN SHEHR NO Three & 86.07 & 99.75 \\
\hline GPS NAWAN SHEHR NO Two & 175.51 & 199.49 \\
\hline GPS DHODIAL NO One & 370.53 & 384.266777 \\
\hline GGPS OCHAR & 77.02 & 159.99 \\
\hline
\end{tabular}

\section{Conclusion}

Spatial analysis shows that there are 153 schools including primary, middle and high standards distributed unevenly in different parts of the city. Results show that there are $17 \%$ schools out of city boundary, which is a major problem be considered carefully by school administrations. This could cause effects on time and cost for students and public access to these schools. The percentage of the middle and high schools is much less in northern and western areas leading to low accessibility. Moreover, one of the middle schools is outside the city boundary. Because of the high slope area, many schools are a 15-25 minutes' walk from the road and could be more dangerous in winter. The accessibility will be more costeffective for the population in south-eastern areas and less effective for north-western areas of the city. The number of primary schools is 127 in Abbottabad, which is higher than both middle and high school standard. Distribution of primary schools is also higher in the eastern side of the city but schools in other areas meet administrative requirements. Euclidean distance showed the average distance among primary schools is about 800 meters, for middle schools, it is 2.6 kilometre's, and for high schools is 3.2 kilometre's. Cost-weighted distance analysis showed that average distance time in the outer areas of the city would take more than the usual time because of the slope and hilly areas. Table 3 shows the average result values of the distance between different aspects.

This study concluded that, because of uneven distributions of schools in this hilly area, there is an urgent need for reorganization and restructuring of both physical and social infrastructure, in order to enhance access to the schools. For instance, when thinking about constructing hostels for students or residential houses for teachers, priority should first be given to those schools with the least accessibility. Likewise when constructing or improving the existing roads from the city towards these schools. The management of the studied schools should use the analysis of this study when preparing the school timetable and calendar so that class sessions end at a time that can allow safe walk of students to their homes, and in deciding the best time for beginning classes for the case of day schools.

This study opens doors for further studies to be done on several factors that get affected by school accessibility. For instance, one may compare factors like; School enrolment rates, attendance, performance, dropout rates, staff turnover rates, students transfer rates and quality of staff between schools with better accessibility and those with least accessibility so as to establish the magnitude of the effects of the schools' inaccessibility.

Table 3: Average distance Results

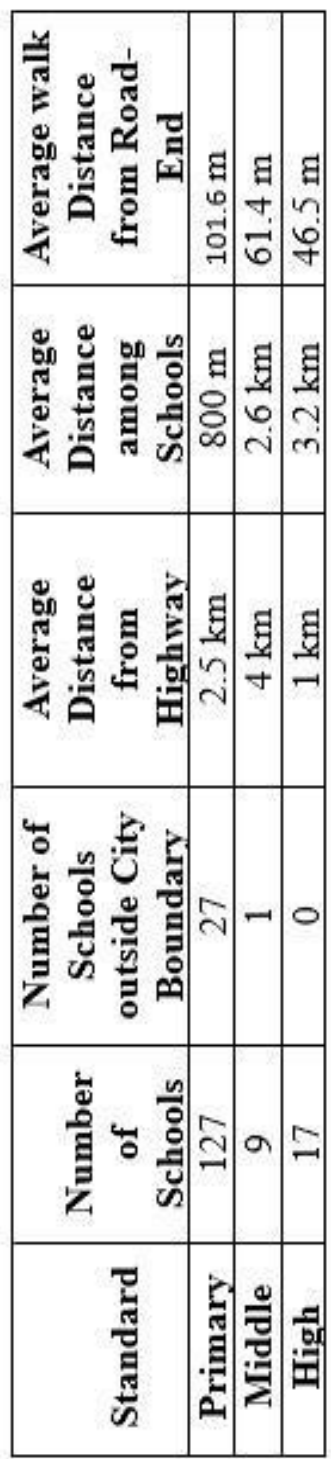




\section{Acknowledgements}

We would like to thank Prof. Shao Zhenfeng and Prof. Huayi Wu, Prof. John van Genderen for their help and support during our studies. Also, many thanks to LIESMARS department for the scholarship.

\section{Funding}

This work was supported in part by the National key R \& $D$ plan on strategic international scientific and technological innovation cooperation special project under Grant 2016YFE0202300, the National Natural Science Foundation of China under Grants 61671332, 41771452, and 41771454, the Natural Science Fund of Hubei Province in China under Grant 2018CFA007.

\section{References}

Al-Enazi, Mazloh, Mesbah, Saleh, and Anwar, Amani. (2016). "Schools Distribution Planning using GIS in Jeddah City". International Journal of Computer Applications, 0975-8887, Vol.138-No.1

Al-Rasheed, Khalid, and El-Gamily, H Hamdy. (2013). GIS as an Efficient Tool to Manage Educational Services and Infrastructure in Kuwait. Journal of Geographic Information System, 4, 75-86

Anderson, Katherine, Ryan, Barbara, Sonntag, William, Kavvada, Argyro, and Friedl, Lawrence. (2017). Earth observation in service of the 2030 Agenda for Sustainable Development. Geo-spatial Information Science. 20:2, 7-96.DOI: 10.1080/10095020.2017.1333230

Asiyanbola, Abidemi. Raimi. (2017). An Evaluation of Public Servant awareness and use of GIS/Remote Sensing in Africa-Nigeria, South African Journal of Geomatics, Vol. 7. No. 1, AARSE2017 Special Edition. http://dx.doi.org/10.4314/sajg.v7i1.3

Awoniyi, Anthony Ilufoye. (2014). Surveying and Geoinformatics Training in Nigeria: Issues and Challenges. FIG Congress 2014: Engaging the Challenges - Enhancing the Relevance Kuala Lumpur, Malaysia 16-21 June

Bishop, Michael P., Shroder, John Jr, Sloan, Valerie. F., Copland, Luke, and Colby, Jeffrey. (1998). Remote sensing and GIS technology for studying lithospheric processes in a mountain environment. Geocarto International,13(4),75-87.

doi:10.1080/10106049809354667

Curtis, Carey. \& Scheurer, Jan. (2017), Performance measures for public transport accessibility: Learning from international practice, The Journal of Transport and Land Use, Vol. 10 No. 1, pp. 93-118. http://dx.doi.org/10.5198/jtlu.2016.683

Demirel Hande. \& Shoman Wasim. (2017). SpatioTemporal Analyses for Dynamic Urban Road Network Management. Transportation Research Procedia. 22:519-528. doi:10.1016/j.trpro.2017.03.070
Fleischmann, Elfrieda Marie-Louise and van der Westhuizen, Christo. (2017). The Interactive-GIS-Tutor (IGIST): An Option for GIS Teaching in Resourcepoor South African Schools, South African Geographical Journal, 99:1, 68-85, DOI: 10.1080/03736245.2016.1208576

Ford Alistair, Barr Stuart, Dawson Richard, and James Philip. (2015). Transport Accessibility Analysis Using GIS: Assessing Sustainable Transport in London, ISPRS International Journal of Geo-Information, 4, 1, 124. doi:10.3390/ijgi4010124

Gong, Jianya, Yue, Peng, Wolday, Tsehaie, Tsai, Fuan, Vyas, Anjana, Wu, Huayi, Gruen, Armin, Wang, Le. \& Musikhin, Igor. (2017). Geoinformatic Education and Outreach: Looking Forward. Geo-spatial Information Science, Vol.20, No.2, 209-217. https://doi.org/10.3929/ethz-b-000192037

Komba, Sotco Claudius. \& Kira, Ernest. (2013). The effectiveness of teaching practice in improving student's teachers teaching skills in Tanzania. Journal of Education and Practice. Vol. 4, No. 1

Lagrab, Waleed, and Aknni, Noura. (2015). Analysis of Educational Services Distribution-Based Geographic Information System (GIS). International Journal of Science and Technology Research, Vol 4, No: 3. ISSN 2277-8616

Li, Deren, Gong, Jianya, and Yue, Peng. (2014): Geoinformatics education in China. Geospatial Information Science, Vol.17, No.4, pp 208-218. DOI: 10.1080/10095020.2014.985282 Li, Deren. (2003). Toward the Development of Remote Sensing and GIS in the 21st Century. Geomatics and information Science. 25(2): 127-131.

Li, Deren, Wang, Mi, Dong, Zhipeng, Shen, Xin, and Shi, Lite. (2017a). Earth Observation Brain (EOB): An intelligent earth observation system. Geo-Spatial Information Science, Vol 20, No. 2, 134-140. DOI: 10.1080/10095020.2017.1329314

Li, Songnian and Chen, Jun. (2017). Supporting future earth with global geospatial information, International of Digital Earth, 10:4, 325-327. doi:10.1080/17538947.2016.1275832

Li. Deren, Wang, Mi, Shen, Xin, and Dong, Zhipeng. (2017b). From Earth Observation Satellite to Earth Observation Brain. Geomatics and Information Science, 42(2):143-149

Mokoena, T. B and Musakwa, W. (2018). Mobile GIS occupancy audit of Ulana informal settlement in Ekurhuleni municipality, South Africa. Geo-Spatial Information Science. https://dio.org/10.1080/10095020.2018.1519349

Musakwa, Walter. (2017). Perspectives on Geospatial Information Technology usage in municipalities and geographic information systems (GIS) education amongst urban planners in Southern Africa. GeoSpatial Information Science, Vol. 20, No.2, 201-208

Scott, Greg, and Rajabifard, Abbas. (2017). Sustainable Development and Geospatial Information: A Strategic 
Framework for Integrating a Global Policy Agenda into National Geospatial Capabilities. Geo-spatial Information Science, Vol. 20, No. 2. 59-76. doi:10.1080/10095020.2017.1325594

Shoman, Wasim, and Demirel, Hande. (2018). SpatioTemporal Evaluation of Transport Accessibility of the Istanbul Metrobus Line. Geocarto International, 135. doi:10.1080/10106049.2018.1524515

Shoman Wasim., Algancı Uğur. \& Demirel, Hande. (2018). A Comparative Analysis of Gridding Systems for Point Based Land-Use Analysis. Geocarto International. https://doi.org/10.1080/10106049.2018.1450449.

Sumari, Neema, Shao, Zhenfeng, and Kira, Ernest. (2017). Challenges and Opportunities for the Advancement of GIS Education in Tanzania. Journal of Education and Practice, 8(28), 67-75.

Sumari, N.S., Shao, Z., van Genderen, J.L., Masakwa, W., Ujoh, F., Washaya, P. \& Gumbo, T. (2019). Status of Geo-Informatics Education and Training in Sub Sahara Africa: Initiatives Taken and Challenges. Journal of Geography in Higher Education; doi: 10.1080/03098265.2019.1599831

Tate, Nicholas, and Jarvis, Claire. (2017). Changing the Face of GIS Education with Communities of Practice, Journal of Geography in Higher Education, 41:3, 327340. DOI: 10.1080/03098265.2017.1315534

Tahir, Andrabi, Das, Jishnu, and Khwaja, Asim Ijaz. (2008). "A Dime a Day: Possibilities and Limits of Private Schooling in Pakistan," Comparative Education Review, 52(3): 329-355

Tsai, Fuan, and Chen, Liang-Chien. (2014). Challenges of remote sensing and spatial information education and technology transfer in a fast-developing industry. ISPRSInternational Archives of the Photogrammetry, Remote sensing and Spatial Information Sciences, Vol: XL-6, doi: 10.5194/isprsarchives-XL-6-103-2014

van Genderen, John. (1992). "Guidelines for Education and Training in Environmental Information Systems in Sub-Sahara Africa: some Key issues." World Bank Report, Guidelines Series, No.1 Washington, D.C. USA, 34pages

Van Genderen, John. (1991). The transfer of remote sensing technology in Asia - the ITC experience. Geocarto International, 6(3), 84-89. doi: 10.1080/10106049109354328

van Genderen, John. (2017). Perspectives on the nature of Geospatial Information, Geo-spatial Information Science, 20:2, 57-58, DOI: 10.1080/10095020.2017.1337320

Wang, Zheye, and Ye, Xinyue. (2018). Space, Time, and Situational Awareness in Aatural Hazards: A Case Study of Hurricane Sandy with Social Media Data. Cartography and Geographic Information Science, 113. doi:10.1080/15230406.2018.1483740 